\title{
Individual differences in magnitude estimates of inferred, remembered, and perceived geographical distance
}

\author{
JOSÉ APARECIDO DA SILVA, ERASMO MIESSA RUIZ, and SUZI LIPPI MARQUES \\ University of São Paulo at Ribeirão Prêto, Ribeirão Prêto, Brazil
}

\begin{abstract}
Three separate groups of observers made magnitude estimates of intercity distance in two sessions separated by an interval of 1 month. The first group of observers estimated intercity distance from memory, using just general knowledge of Brazilian geography (inferred distance). The second group estimated intercity distance from memory after studying a map for a period of $7 \mathrm{~min}$ (remembered distance). The third group made the estimates while viewing a map (perceived distance). It was found that (1) although the exponent varied from one individual to another, the psychophysical power law described well the inferred, remembered, and perceived magnitude estimates of intercity distance; (2) the following ordinal relationship occurred between the sizes of the mean exponents: perceived > remembered > inferred; (3) the correlations between observers' exponents for the first and second sessions for all types of estimate were fairly high and positive; and (4) the individual differences observed in the exponents of the psychophysical power law for magnitude estimates of inferred, remembered, and perceived intercity distance were stable, at least for an interval of 1 month between sessions.
\end{abstract}

The development of direct estimation methods by S. S. Stevens and collaborators (e.g., S. S. Stevens, 1975) was followed by an interest in the variability of individual power functions. In fact, many experiments have reported considerable individual differences in the exponent of Stevens's power law $R=K S^{n}$ for different sensory or perceptual attributes (Algon \& Marks, 1984; Baird, Green, \& Luce, 1980; Cook, 1978; Ekman, Hosman, Lindman, Ljungberg, \& Akesson, 1968; Engeland \& Dawson, 1974; Jones \& Marcus, 1961; Ramsay, 1979; Rule, 1966; Rule \& Markley, 1971; Schneider, 1980; J. C. Stevens \& Guirao, 1964). The outcomes of these experiments have raised the question of whether the variability observed in the exponents reflects genuine perceptual differences or some type of cognitive factor, such as a response bias, that affects observers' responses to stimulus intensities in a scaling task. To attack this question experimentally, Duda (1975) considered three models proposed to interpret power functions. These models also specify how sensory, stimulus, and response variables determine observers' judgmental behavior in a scaling task. A correlational analysis on individual differences in exponents was undertaken to test the predictions derived from each model. The results showed that response variables are important determinants of judgmental behavior in psychophysical scaling. These findings led Duda to suggest that observers'

This research was supported by Grants 85/2135-9, 85/2199-7, and 85/1625-2 from Fundação de Amparo à Pesquisa do Estado de São Paulo (FAPESP), Brazil. The preparation of the manuscript was supported by Grant 30.0567-85 from Conselho Nacional de Desenvolvimento Científico e Tecnológico (CNPq). Requests for reprints should be sent to J. A. Da Silva, Department of Psychology, University of São Paulo, 14049 Ribeirão Prêto, São Paulo, Brazil. responses to stimulus magnitudes in a scaling task are largely cognitive.

Correlational studies of stability of individual psychophysical power function exponents have produced inconclusive and sometimes contradictory results, even when the same sensory or perceptual attribute-for example, area or length - has been used. Jones and Woskow (1962) and Ekman et al. (1968) reported low but significant correlations between exponents for two stimulus continua when the same response continuum was used. In addition, Ekman et al. reported high correlations when there was no change in either stimulus or response continuum. Rule (1966) found high and positive correlations both when they were computed between continua and when they were test-retest reliability of coefficients. Also, Rule and Markley (1971) reported higher correlations for individual exponents for conditions with the same dependent variable than for conditions with the same set of stimuli. These correlations permitted them to conclude that each observer exhibits his/her own characteristic range of responses within a given response system. In other words, the differences in individual exponents were attributed largely to differences in response bias. Other studies compared singly the psychophysical power function curve obtained in a session with that obtained in another session separated by either long or short intersession intervals. For example, Verrillo and Chamberlain (1971) compared the psychophysical power function curve of a single observer with that obtained from the same observer 3 years later. Both the slopes and the numerical magnitude estimates were nearly identical in the two sessions. Also, Petrosino, Fucci, and Harris (1985) showed good agreement between the magnitude estimate functions obtained 
in three different sessions from the same observers. Similar results were found by Walsh and Browman (1978), Schneider (1980), and Petrosino and Fucci (1985).

The first study that investigated systematically the stability of individual power function exponents over time was carried out by Teghtsoonian and Teghtsoonian (1971). They had observers give magnitude estimates of area and length in five sessions separated by $24-h$ intervals and again after an intersession interval of 1 year. Individual exponents for both continua were not stable when the time between sessions was $24 \mathrm{~h}$ or longer. In another study, they confirmed these results and suggested that sessionto-session correlations are transitory and that "enduring characteristics of the observer contribute only a small portion of the variability in individual power law exponents" (Teghtsoonian \& Teghtsoonian, 1983, p. 203). Other studies have not confirmed these results. For example, Engeland and Dawson (1974) found subjective area and loudness to be stable with no delay and with a 1-week intersession interval. All correlations between magnitude estimation and cross-modality matching obtained in two sessions were significant. Using the cross-modality matching procedure to match loudness to apparent duration of time and vice versa, Wanschura and Dawson (1974) found positive and significant correlations across six sessions separated by an intersession interval of $24 \mathrm{~h}$. Logue (1976), using magnitude estimation, reported that individual exponents for loudness are fairly stable when the intersession interval was 11 weeks. Walsh and Browman (1978), using a brightness-loudness matching task, reported stability for power function exponents for individuals over 2 months. Their data indicated that power function exponents for individuals remained constant over many testing sessions and fairly long intersession intervals. Also, Hellman (1981) reported that individual loudness functions remained stable for up to 6 weeks despite changes in stimulus frequency. Similarly, Verrillo (1983), employing the method of absolute magnitude estimation, found a high temporal stability for two groups of observers who estimated line length in two sessions. One group was retested after 1 year and the other after 2 years. This temporal stability was observed both in the exponent values, individual and group, of the power functions and in the numerical estimates themselves. The observers in the present experiment also made magnitude estimates twice, with 1 month separating the two sessions. Our primary concern was with the stability of individual exponents for estimated intercity distances over a long intersession interval. The conditions and instructions used were quite similar to those used by Kerst and Howard (1978), in whose study observers made inferred, remembered, and perceived estimates of intercity distances.

\section{METHOD}

\section{Observers}

Sixty undergraduate students at the University of São Paulo, Ribeirão Prêto, served as subjects in two separate sessions. They were randomly assigned to three groups. Because 2 observers of each group failed to appear for Session 2, the final Ns were 18 for each group. No subject had experience with the method of magnitude estimation.

\section{Materials and Procedure}

The observers recorded their estimates of the linear distances between Brasilia (the federal capital) and the capitals of each of the 25 states of Brazil on a previously prepared package of 26 response sheets. Sheet 1 contained written instructions. Following the instruction sheet that constituted the cover page, each sheet contained only the names of the federal capital (Brasilia) and another capital (for example, Brasilia-São Paulo). All observers made magnitude estimates of all 25 pairs of intercapital distances in two sessions separated by 1 month. The second session was a replication of the first session, in which the linear distance between Brasilia and the capital of each Brazilian state was judged only once. Each observer received different random orders of the 25 response sheets in Sessions 1 and 2. Within each group the observers received different random orders. The observers were tested in groups during a class period; they did not know they would be tested a second time until that moment arose (in the classroom). No participant required more than 20 min to complete the task.

The first group of observers, Group Inferred, judged the intercapital distance from memory. They made the judgments using their general knowledge of Brazilian geography. The second group, Group Remembered, estimated the intercapital distances from memory immediately after studying the map. The third group, Group Perceived, made the estimates while viewing the map.

An outline map of Brazil $(21.6 \times 33 \mathrm{~cm})$, showing only the boundaries, the names of the states, and the name of the capital of each state, was provided for all observers in Groups Remembered and Perceived. Observers in Group Inferred received only the package of 26 response sheets with the instruction sheet as the front cover. Observers in Group Remembered were handed copies of the map and then were given a brief instruction sheet that asked them to study the map for a 7-min period to get a good idea of the relative locations of the states. Immediately following this period of study, the experimenters collected the maps and distributed the package of response sheets with the accompanying instruction sheet. The observers in Group Perceived received the package of response sheets, the instruction sheet, and a copy of the map all at the same time.

The method of magnitude estimation was used, with the linear distance between Brasilia and São Paulo as a modular distance. This standard was chosen because it was very familiar to all observers. The instructions given to the observers emphasized that they could use any numbers that seemed appropriate to represent the linear distance between Brasilia and the capital of each state, including values less than 1 (fractions or decimals). Also, it was explained that the linear distance between Brasilia and São Paulo was to serve as a standard and that it should be assigned a value of 100 units.

\section{RESULTS AND DISCUSSION}

\section{The Psychophysical Function}

For each observer in Sessions 1 and 2, a least squares fit of $\log$ magnitude estimates as a function of log actual distances between Brasilia and the capital of each state was obtained. The assigned modulus was treated as a judgment (equal to 100 ). The exponent $(n)$, the scale factor, and the coefficient of determination $\left(r^{2}\right)$ were computed for each observer. These values, together with the range of exponents and standard deviations, are presented in Table 1. The mean exponents for Groups Inferred, Remembered, and Perceived were .76, .86, and 1.05, respectively, for Session 1 , and $.68, .72$, and 1.06 for Session 2 . A $3 \times 2$ (group $\times$ session, with repeated measures on the second factor) analysis of variance carried out on the individual exponents yielded a significant ef- 
Table 1

Mean Exponents $(n), S D s$, Coefficients of Determination $\left(r^{2}\right)$, and Session 1-Session 2 Correlations $\left(r_{12}\right)$ Between Exponents for Inferred, Remembered, and Perceived Magnitude Estimates of Intercity Distances

\begin{tabular}{|c|c|c|c|c|c|c|c|c|c|}
\hline \multirow[b]{2}{*}{ Group } & \multicolumn{4}{|c|}{ Session 1} & \multicolumn{4}{|c|}{ Session 2} & \multirow[b]{2}{*}{$r_{12}$} \\
\hline & $n$ & $S D$ & Range & $r^{2}$ & $n$ & $S D$ & Range & $r^{2}$ & \\
\hline Inferred & .76 & .33 & $.12-1.33$ & .52 & .68 & .30 & $.12-1.20$ & .51 & $.77^{*}$ \\
\hline Remembered & .86 & .27 & $.03-1.26$ & .58 & .72 & .18 & $.42-1.09$ & .59 & $.43 \dagger$ \\
\hline Perceived & 1.05 & .18 & $.81-1.43$ & .92 & 1.06 & .21 & $.74-1.52$ & .93 & $.81^{*}$ \\
\hline
\end{tabular}

fect of group $[F(2,51)=10.56, p<.001]$. The effect of session was significant $[F(1,51)=7.16, p=.009]$, and the interaction of group $\times$ session was marginally significant $[F(2,51)=2.71, p=.07]$. Subsequent comparisons by $t$ test, evaluated at an alpha level of .05 , showed that the mean exponent for Group Remembered was significantly larger in Session 1 than in Session 2; for Groups Inferred and Perceived the comparisons were nonsignificant. Also, comparisons made between the mean exponents of each group showed that the mean exponent for Group Perceived was greater than those for Groups Inferred and Remembered, and that for Group Remembered was larger than that for Group Inferred. This pattern of results occurred for both sessions. The mean exponents for Group Perceived showed good agreement with those obtained and analyzed by Baird (1970), Da Silva and Macedo (1983), Osaka (1983), and Wiest and Bell (1985), who found mean exponents close to 1.0 for the power function relating perceived distance (or length) to physical distance (or length). In addition, the results confirm the ordinal relationship between the size of the mean exponents, that is, perceived $>$ remembered $>$ inferred, as suggested by Mulholland, Da Silva, Janczura, and Penso (1981) and Wiest and Bell (1985). However, even though the results support these previous studies, demonstrating smaller exponents for Group Remembered than for Group Perceived for psychophysical functions, they did not confirm the hypothesis proposed by Kerst and Howard (1978) that the remembered estimates involve a second power transformation identical to the original perceived one, so that the remembered exponent is approximately equal to the square of the perceived exponent.

\section{Session-to-Session Correlation \\ Between Exponents}

Pearson correlation coefficients were calculated between the individual exponents obtained in Sessions 1 and 2 for each group. These correlations are shown in the last column of Table 1 . The correlations between the exponents obtained in Sessions 1 and 2 were $.77(p<.001)$ for Group Inferred, $.43(.05<p<.10)$ for Group Remembered, and .81 $(p<.001)$ for Group Perceived. All correlations were fairly high and positive. Taken together, these significant correlations computed between the individual exponents obtained from the first and second sessions indicate that persisting individual differences in exponents were found in all of the groups studied, despite an interval of 1 month between sessions. Of greater interest is the confirmation of earlier reports of individual differences in the exponents (e.g., Da Silva \& Fukusima, 1986; Teghtsoonian \& Teghtsoonian, 1971, 1983; Verrillo, 1983). The results presented here demonstrate that these differences are maintained over a period as long as 1 month.

It is of interest to examine the significant difference found between the mean exponents of Sessions 1 and 2 obtained for Group Remembered. This difference probably occurred because in Session 1 the brief instructions asked the observers only to study the map for a 7-min period to get a good idea of the relative locations of the states; they did not know they would be asked to estimate linear distances between Brasilia and the other capitals. In Session 2, although the brief instructions were identical to those used in Session 1, the observers probably supposed that they would be asked to estimate linear distances between capitals. Because of this they could study the map attending exclusively to the linear distances between Brasilia and the other capitals. To investigate this possibility, we carried out an additional experiment, in which, in both sessions, the observers received only a complete instruction sheet asking them to study the map for a period of $7 \mathrm{~min}$, attending to the linear distances between Brasilia and the other capitals. The interval between sessions was 1 month. The mean exponents were $.93(S D=.18)$ for Session 1 and $.88(S D=.17)$ for Session 2 . This difference was nonsignificant $[t(18)=1.15, p=.27]$. However, the Pearson correlation coefficient calculated between the individual exponents obtained in Sessions 1 and 2 was equal to $.38(p=.10)$. This value is close to the previously obtained value of .43 . Therefore, it appears that this modification in the instructions reduced the difference between the mean exponents of Sessions 1 and 2, but did not change substantially the value of the correlation coefficient.

In summary, the results described here suggest that the psychophysical power law describes individual performance as well as average group performance, and that the inferred, remembered, and perceived exponents for linear distance estimates manifest a temporal stability of at least 1 month.

\section{REFERENCES}

Algon, D., \& Marks, L. E. (1984). Individual differences in loudness processing and loudness scales. Journal of Experimental Psychology: General, 113, 571-593.

BAIRD, J. C. (1970). Psychophysical analysis of visual space. New York: Pergamon.

BaIRD, J. C., Green, D. M., \& LuCE, D. (1980). Variability and sequential effects in cross-modality matching of area and loudness. Journal of Experimental Psychology: Human Perception \& Performance, 6, 277-289.

Cook, M. (1978). The judgment of distance on a plane surface. Perception \& Psychophysics, 23, 85-90.

DA Silva, J. A., \& FukUsima, S. S. (1986). Stability of individual psychophysical functions for perceived distance in natural indoor and outdoor settings. Perceptual \& Motor Skills, 63, 891-902. 
Da Silva, J. A., \& MAcedo, L. (1983). Efeitos de algumas variáveis experimentais sobre a invariância das escalas perceptivas. Arquivos Brasileiros de Psicologia, 39, 48-70.

DuDA, P. D. (1975). Tests of the psychological meaning of the power law. Journal of Experimental Psychology: Human Perception \& Performance, 104, 188-194.

Ekman, G., Hosman, B., Lindman, R., Ljungberg, L., \& AKesson, C. A. (1968). Interindividual differences in scaling performance. Perceptual \& Motor Skills, 26, 815-823.

ENGELAND, W., \& DAWSON, W. E. (1974). Individual differences in power functions for a 1-week intersession interval. Perception \& Psychophysics, 15, 349-352.

Hellman, R. P. (1981). Stability of individual loudness functions obtained by magnitude estimation and production. Perception \& Psychophysics, 29, 63-70.

JoNES, F. N., \& MARCUS, M. J. (1961). The subject effect in judgments of subjective magnitude. Journal of Experimental Psychology, 61, 40-44.

JoNES, F. N., \& Woskow, M. (1962). On the relationship between estimates of magnitude of loudness and pitch. American Journal of Psychology, 75, 669-671.

Kerst, S. M., \& Howard, J. H., JR. (1978). Memory psychophysics for visual area and length. Memory \& Cognition, 6, 327-335.

LOGUE, A. W. (1976). Individual differences in magnitude estimation of loudness. Perception \& Psychophysics, 19, 279-280.

Mulholland, T. M., Da Silva, J. A., Janczura, G. A., \& Penso, M. A. (1981, October). Estimação de razão de distância em escala geográfica. Paper presented at the 14th Reunião Anual da Sociedade de Psicologia de Ribeirão Prêto, Ribeirão Prêto.

OsakA, N. (1983). Memory psychophysics for perceived length and area: A psychophysical approach to memory processes. Faculty of Letters Review, 17, 15-28.

Petrosino, L., \& Fucci, D. (1985). Stability of temporal resolution of the tactile sensory system for a one-year interim. Perceptual \& Motor Skills, 60, 590.

Petrosino, L., Fucci, D., \& Harris, D. (1985). Effects of singlesession repetitive judgments on magnitude estimation scales for lingual vibrotactile sensation. Perception \& Psychophysics, 37, 205-208.

RAMSAY, J. O. (1979). Intra- and Interindividual variation in the power law exponent for area summation. Perception \& Psychophysics, 26, 495-500.

RULE, S. J. (1966). Subject differences in exponents of psychophysical power functions. Perceptual \& Motor Skills, 23, 1125-1126.

Rule, S. J., \& MARKLEY, R. P. (1971). Subject differences in crossmodality matching. Perception \& Psychophysics, 9, 115-117.

SCHNEIDER, B. (1980). Individual loudness functions determined from direct comparisons of loudness intervals. Perception \& Psychophysics, 28, 493-503.

Stevens, J. C., \& Guirao, M. (1964). Individual loudness functions. Journal of the Acoustical Society of America, 36, 2210-2213.

Stevens, S. S. (1975). Psychophysics: Introduction of its perceptual, neural, and social prospects (G. Stevens, Ed.). New York: Wiley.

Teghtsoonian, M., \& Teghtsoonian, R. (1971). How repeatable are Stevens's power law exponents for individual subjects? Perception \& Psychophysics, 10, 147-149.

Teghtsoonian, M., \& Teghtsoonian, R. (1983). Consistency of individual exponents in cross-modal matching. Perception \& Psychophysics, 33, 203-214.

VerriLlo, R. T. (1983). Stability of line-length estimates using the method of absolute magnitude estimation. Perception \& Psychophysics, 33, 261-265.

Verrillo, R. T., \& Chamberlain, S. C. (1971). Direct scaling of vibrotaction: An individual replication. Psychonomic Science, 22, 225-226.

WALSH, J. K., \& BRowman, C. P. (1978). Intraindividual consistency on a cross-modality matching task. Perception \& Psychophysics, 23, 210-214.

Wanschura, R. G., \& Dawson, W. E. (1974). Regression effect and individual power functions over sessions. Journal of Experimental Psychology, 102, 806-812.

WIEST, W. M., \& BELL, B. (1985). Stevens's exponent for psychophysical scaling of perceived, remembered, and inferred distance. Psychological Bulletin, 98, 457-470.

(Manuscript received for publication January 21, 1987.) 